\title{
Le Québec entre sécularisme et post-sécularité
}

Le cas du débat autour du programme d'Éthique et culture religieuse

Quebec zwischen Säkularismus und Post-Säkularismus : Die Frage des

Unterrichts in Ethik und Religionskultur

Quebec between Secularity and Post-Secularity: The Debate about the Ethics and Religious Culture Program

\section{Dany Rondeau}

\section{(2) OpenEdition \\ Journals}

Édition électronique

URL : http://journals.openedition.org/ceg/2899

DOI : $10.4000 /$ ceg.2899

ISSN : 2605-8359

Éditeur

Presses Universitaires de Provence

Édition imprimée

Date de publication : 26 avril 2018

Pagination : 89-101

ISBN : 979-10-320-0160-8

ISSN : 0751-4239

\section{Référence électronique}

Dany Rondeau, "Le Québec entre sécularisme et post-sécularité », Cahiers d'Études Germaniques [En ligne], 74 | 2018, mis en ligne le 26 octobre 2019, consulté le 28 novembre 2020. URL : http:// journals.openedition.org/ceg/2899; DOI : https://doi.org/10.4000/ceg.2899 


\title{
Le Québec entre sécularisme et post-sécularité Le cas du débat autour du programme d'Éthique et culture religieuse
}

\author{
Dany Rondeau \\ Université du Québec à Rimouski (Canada)
}

Plusieurs débats sociaux au cours des quinze dernières années montrent que le Québec oscille entre sécularisme et post-sécularité. Sur le plan de l'État, de son fonctionnement, de ses institutions et des choix qu'il fait, le Québec est post-séculier. Néanmoins, un nombre important de Québécois considère que la laïcité de l'État n'est pas encore tout à fait réalisée ou qu'elle doit se concrétiser dans des lois qui affirment clairement la neutralité de l'État et sa séparation d'avec les religions. Dans cette perspective, toute attitude d'ouverture ou de tolérance à l'égard des religions, des pratiques religieuses, de l'expression de convictions religieuses est perçue comme contraire à la laïcité. D'autres estiment plutôt que le Québec est déjà une société post-sécularisée dans laquelle les convictions religieuses n'exercent plus aucune influence sur la chose politique ou publique et que l'attitude de l'État, ouvert au pluralisme, est justifiée par les droits reconnus dans les chartes canadienne et québécoise.

La posture idéologique des premiers correspond à ce que Jürgen Habermas et Jean-Marc Ferry appellent le sécularisme. Celle des seconds, à ce qu'ils définissent comme la pensée post-séculière. Dans son sens objectif et théorique, le sécularisme est une posture qui vise la sécularisation de la société et défend la laïcité de l'État de même que le principe de séparation de l'État et de la religion. Dans la réalité des sociétés concernées, il s'accompagne souvent d'un scientisme naturaliste hostile aux religions, faisant l'apologie de l'athéisme et reléguant le domaine des croyances à de l'affabulation. De son côté, le post-sécularisme se défınirait plutôt comme une caractéristique sociologique correspondant à l'apparition de nouveaux modes du croire non institutionnels dans les sociétés laïques. Pour Ferry, " la postsécularité, loin d'indiquer un retour vers les époques préséculières, suggère au contraire que la sécularisation se poursuive non pas maintenant contre la religion, mais à présent avec elle et en son sein, peut-être pour le bénéfice d'une réconciliation de la raison critique et de la foi ${ }^{1}$ ". Autrement dit, une société post-séculière est une société dans laquelle la séparation entre l'État et les religions serait complétée. La ou les religions n’y seraient pas

1. Jean-Marc Ferry, La Raison et la foi, Paris, Éditions Pocket, 2016, p. 49. 
perçues comme une menace pour la laïcité, mais plutôt considérées comme des phénomènes ethnoculturels parmi d'autres qui devraient jouir du même respect que les autres expressions du pluralisme. C'est cette attitude d'ouverture à l'égard de la religion, à l'égard des religions, qui différencie et oppose les " postséculiers " aux " sécularistes".

Au Québec, la controverse autour du programme Éthique et culture religieuse est un bon exemple de cette tension entre sécularisme et post-sécularisme. En 2005, pour compléter le processus de déconfessionnalisation du système scolaire, le gouvernement du Québec décide de remplacer l'enseignement moral et religieux confessionnel ${ }^{2}$ par un cours unique, obligatoire, d'éthique et de culture religieuse. Ce programme, mis en place en 2008, conjugue un enseignement de l'éthique dans une perspective séculière, critique et humaniste avec un enseignement culturel des religions. Cependant, cette conjonction de l'éthique et de la culture religieuse ne fait pas l'unanimité et ce programme n'a cessé d'être attaqué par ceux qui considèrent qu'il constitue un retour de la religion à l'école et un enseignement confessionnel déguisé.

Dans ce texte, je ferai un bref historique des débats qui constituent des étapes marquantes de la tension sociale et politique entre sécularisme et post-sécularité (1). Pour mieux faire saisir en quoi le programme Éthique et culture religieuse contribue à exacerber cette tension, j'en présenterai succinctement les grandes lignes (2) et résumerai les critiques qui lui sont adressées par les tenants d'une posture séculariste (3). Enfın, je tenterai d'apporter quelques réponses à ces critiques qui montrent bien en quoi le programme s'inscrit lui-même dans une perspective post-séculière, respectueuse de la laïcité de l'État, mais soucieuse du pluralisme de la société québécoise (4).

\section{Le Québec entre sécularisme et post-sécularité}

Le Québec a connu, au début des années soixante, une "Révolution tranquille " qui a constitué une étape importante dans le processus de sécularisation de la société québécoise. La création, en 1964, du ministère de l'Éducation qui prend en charge le système scolaire jusque-là administré par les communautés religieuses en constitue une étape importante. Pendant les quatre décennies qui ont suivi, la religion ne représente pas vraiment un objet de débat public, ni un sujet d'actualité, la Révolution tranquille ayant opéré une rupture avec la mainmise de l'Église sur la société. Les choses changent au tournant des années 2000, alors que plusieurs événements polarisent les opinions au sujet de la religion, plus précisément au sujet de ses manifestations et de son expression dans l'espace public. Ainsi, en 2002 et 2006, la Cour suprême du Canada rend

2. Il s'agissait en fait d'un système d'options entre lesquelles les élèves (ou leurs parents) devaient choisir. Les options, au nombre de trois, étaient: l'enseignement moral et religieux catholique, l'enseignement moral et religieux protestant ou l'enseignement moral non confessionnel. Ce système d'options devenait indéfendable car il accordait un privilège à deux religions, ce qui contrevenait à la Charte canadienne des droits et libertés et à la Constitution canadienne. 
des jugements très controversés concernant le port du kirpan à l'école par des élèves de confession sikhe au motif de la liberté de conscience et de religion. Cette controverse a déclenché ce qu'on a appelé la crise des accommodements raisonnables ${ }^{3}$ qui incitera le gouvernement québécois à mettre en place, en 2007, la Commission de consultation sur les pratiques d'accommodement reliées aux différences culturelles, communément appelée la Commission Bouchard-Taylor, du nom de ses présidents. En réalité, c'est pour répondre à la pression publique afın que soient balisées les demandes d'accommodements religieux que cette commission est créée. C'est la laïcité et la place de la religion dans l'espace public qui en sont les enjeux centraux. Cette commission servira en quelque sorte de catharsis collective. Elle permettra à plusieurs personnes venues s'y faire entendre d'exprimer des sentiments antireligieux et anti-immigration. Elle a aussi assuré une certaine structuration du débat autour de la diversité culturelle et religieuse et mené à certains consensus qui sont néanmoins restés lettre morte.

En février 2010, un groupe d'intellectuels québécois fait paraître le Manifeste

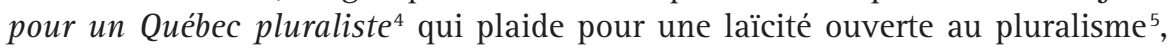
auquel répond presque immédiatement un autre groupe par sa Déclaration des intellectuels pour la laïcité ${ }^{6}$ qui considère qu'il n'y a pas une laïcité ouverte ou

3. L'obligation d'accommodement est un principe du droit québécois et du droit canadien reconnu comme faisant partie du droit à l'égalité, qui a pour fin de corriger une discrimination causée par l'application mur-à-mur d'une norme. Elle oblige les organisations publiques et privées à prendre des mesures raisonnables, c'est-à-dire qui n'entraînent pas une contrainte excessive, afin de garantir aux personnes un traitement égal. Dans le cas mentionné, la norme qui consiste à ne pas avoir sur soi un couteau à l'école porte atteinte à la liberté de religion de l'élève sikhe. La Cour suprême du Canada a rappelé à l'école son obligation d'accommodement raisonnable. Les deux parties se sont entendues pour que l'élève porte son kirpan cousu sous ses vêtements.

4. Manifeste pour un Québec pluraliste. Texte paru dans le quotidien Le Devoir, le 3 février 2010. En ligne: [http://www.ledevoir.com/societe/actualites-en-societe/282309/manifeste-pour-unquebec-pluraliste].

5. Dans un texte précédent, Jocelyn Maclure, un des auteurs principaux du Manifeste pour un Québec pluraliste, défınit ainsi ce qu'est la laïcité ouverte: "Un régime de laïcité "ouverte" cherche à éviter que la laïcité soit en fait une morale antireligieuse. Un tel régime de laïcité est ouvert à la présence de la religion ou de toutes autres doctrines et mouvements de pensée dans l'espace public, dans les limites du respect des droits et libertés des autres citoyens. " "Les raisons de la laïcité ouverte " paru dans Le Devoir, 24 novembre 2008. En ligne: [http:// www.ledevoir.com/non-classe/218244/les-raisons-de-la-laicite-ouverte]. La notion de " laïcité ouverte " apparaît une première fois dans le Rapport Proulx où il est question de la place de la religion à l'école laïque. Le rapport exprime ainsi sa " préférence pour une laïcité ouverte où l'on est généralement prêt à faire place à un enseignement culturel de la religion et à une animation commune pour les diverses religions " (p. 145). Elle est également définie comme une " perspective [qui] fait place à un enseignement culturel des religions et des visions séculières du monde; elle reconnaît la dimension spirituelle de la personne et permet donc aux écoles qui le souhaitent de se doter d'un service d'animation de la vie religieuse et spirituelle commun à tous. Elle accepte aussi que, dans le cadre de sa mission de service à la communauté, l'école puisse, en dehors des heures d'enseignement et compte tenu de ses priorités, mettre ses locaux à la disposition des confessions désireuses d'organiser elles-mêmes des services pour leurs membres " (p. 229) Laïcité et religions. Perspectives nouvelles pour l'école québécoise, Gouvernement du Québec, ministère de l'Éducation, 1999.

6. Déclaration des Intellectuels pour la laïcité - Pour un Québec laïque et pluraliste, paru dans le quotidien Le Devoir, le 16 mars 2010. En ligne: [http://www.ledevoir.com/societe/actualites- 
fermée, mais que la laïcité requiert une complète séparation de l'État d'avec la religion. Ce débat est probablement celui qui fait le mieux ressortir la tension entre sécularisme et post-sécularité en raison de conceptions différentes de la laïcité. On peut qualifier la position des auteurs du premier texte à la fois de post-séculière et de libérale. Post-séculière, car elle affirme que la laïcité est un fait établi, " la séparation de l'Église et de l'État, [ayant été] explicitement reconnue par nos tribunaux dès les années 1950 »; libérale, parce qu'elle prend appui sur la défense des droits et de l'égalité.

C'est à tort que l'on revendique parfois la laïcité comme si ses principes étaient absents de notre culture publique. Au Québec, l'État élabore les normes collectives indépendamment des groupes religieux ou de conviction. Il exerce sa neutralité en s'abstenant de favoriser ou de gêner, directement ou indirectement, une religion ou une conception séculière de l'existence, dans les limites du bien commun. Cette orientation politique répond à l'exigence de protéger la liberté de conscience et sa libre expression, de même que l'égalité des citoyens. Cela signifie que les droits civiques et politiques ne sont pas conditionnels à l'abdication des croyances et des pratiques de ceux qui les expriment ${ }^{7}$.

Les auteurs du deuxième texte considèrent au contraire que la laïcité de l'État n'est jamais garantie tant qu'elle n'est pas affirmée dans une loi. Ils adoptent ainsi une position séculariste au sens donné plus tôt à ce terme:

Pour être neutre, l'État doit se déclarer neutre. Bien que les tribunaux aient statué qu'il n’y avait pas de religion d'État au Québec et au Canada, nos législations souffrent d'un déficit en cette matière puisque la laïcité de l'État n'est nulle part affirmée. Le principe de la séparation des religions et de l'État a été érigé à la pièce par les tribunaux, et rien n'empêcherait que ce principe soit un jour déconstruit à la faveur de revendications contraires ou de nouvelles interprétations juridiques. La protection législative de la laïcité est donc essentielle ${ }^{8}$.

Le principal objet d'affrontement - ou le déclencheur de cet échange - est la proposition d'interdire le port de signes religieux par les agents de l'État. Les auteurs du premier texte considèrent cette interdiction discriminatoire, mais surtout ils n'en voient pas la "nécessité sociale ", laissant entendre que le port de signes religieux ne constitue pas une menace pour la laïcité ou la neutralité de l'État.

[L]'interdiction pure et simple de toute manifestation d'appartenance religieuse ne répond à aucune nécessité sociale. Une telle interdiction aurait un effet discriminatoire, car elle ne viserait que les croyants appartenant aux religions comportant des prescriptions vestimentaires ou alimentaires. Mais surtout, elle serait disproportionnée par rapport aux objectifs, notamment la neutralité des services publics? .

L'argument des auteurs du second texte est plus court et plus direct: " La neutralité de l'État s'exprime par la neutralité de l'image donnée par ses

en-societe/285021/declaration-des-intellectuels-pour-la-laicite-pour-un-quebec-laique-etpluraliste].

7. Manifeste pour un Québec pluraliste.

8. Déclaration des Intellectuels pour la laïcité - Pour un Québec laïque et pluraliste.

9. Manifeste pour un Québec pluraliste. 
représentants. Ces derniers doivent donc éviter d'afficher leur appartenance religieuse, philosophique ou politique ${ }^{10}$."

Cette divergence de points de vue sur les exigences de la laïcité se transposera dans le débat entourant le projet de charte des valeurs québécoises ou charte de la laïcité. En 2013, le gouvernement du Parti québécois soumet à l'Assemblée nationale le projet de loi 60 intitulé Charte affirmant les valeurs de laïcité et de neutralité religieuse de l'État ainsi que d'égalité entre les femmes et les hommes et encadrant les demandes d'accommodement. Une des dispositions de ce projet de loi prévoit justement d'interdire le port de signes religieux ostentatoires par les agents de l'État. Une commission parlementaire est instituée devant laquelle plusieurs mémoires en faveur et contre le projet de loi sont présentés par des citoyens, des associations, des universitaires. Plusieurs de ces mémoires défendent une position hostile à l'égard des religions et plus particulièrement à l'égard de l'islam, la plus touchée par l'interdiction éventuelle du port de signes religieux.

Finalement, bien que près de la moitié des Québécois y soient favorables selon plusieurs sondages réalisés au cours de l'année 2014, le projet de loi ne sera jamais voté. Suite au déclenchement des élections par le gouvernement, qui en a fait un enjeu électoral, les travaux de la commission parlementaire seront suspendus. Ce gouvernement ne sera pas réélu, mais le projet de charte aura eu un effet certain sur le climat social et opposé encore davantage les défenseurs d'une laïcité à concrétiser, les sécularistes, et les défenseurs du pluralisme, les post-séculiers.

\section{Le programme Éthique et culture religieuse}

C'est donc sur cet arrière-fond polémique que se déploie la controverse autour du programme Éthique et culture religieuse (ÉCR) ${ }^{11}$. Avant de parler des objections qu'il soulève et de montrer en quoi ces objections relèvent d'une position séculariste, il convient de présenter brièvement ce programme.

L'instauration du programme ÉCR constitue la dernière étape de la déconfessionnalisation du système scolaire. Il constitue également une solution $\mathrm{au}$ problème juridique de discrimination à l'égard de plusieurs religions qu'exerçait l'ancien programme en n'offrant que l'enseignement religieux catholique ou protestant. Sur un plan sociopolitique, il se veut une réponse constructive à la question de savoir comment gérer la diversité et le pluralisme

10. Déclaration des Intellectuels pour la laïcité - Pour un Québec laïque et pluraliste.

11. Il faudrait aussi ajouter qu'un des débats consécutifs à la Commission Bouchard-Taylor concerne la distinction entre multiculturalisme et interculturalisme. Certains, comme Gérard Bouchard, considèrent l'interculturalisme comme un modèle de gestion politique de la diversité culturelle propre au Québec et distinct du multiculturalisme qui serait le modèle canadien (voir Gérard Bouchard, L'interculturalisme. Un point de vue québécois, Montréal, Boréal, 2012); d'autres affirment plutôt qu'il n'y a pas de différences significatives entre les deux modèles, ce qui permettra aux détracteurs du programme ÉCR de prétendre que celui-ci n'est qu'un instrument pour endoctriner les élèves au multiculturalisme. 
croissants de la société québécoise. Cette intention est explicite dès les premières pages du programme:

Comme plusieurs sociétés démocratiques, le Québec se caractérise par un pluralisme grandissant. Ce pluralisme se manifeste notamment dans la diversité des valeurs et des croyances que préconisent des personnes et des groupes et qui contribuent à façonner la culture québécoise. Facteur important d'enrichissement, la diversité peut parfois devenir une source de tension ou de conflit. Pour vivre ensemble dans cette société, il est nécessaire d'apprendre collectivement à tirer profit de cette diversité. Il importe dès lors de s'y sensibiliser et d'entreprendre une réflexion et des actions favorisant le bien commun. Le programme d'éthique et culture religieuse entend contribuer à cet apprentissage ${ }^{12}$.

L'éducation au vivre ensemble dans la reconnaissance de la valeur du pluralisme constitue donc la visée, l'objectif principal de ce programme, enseigné de la première année du primaire à la dernière année du secondaire. Le postulat sur lequel il repose est que des citoyens ouverts à la diversité, qui ne perçoivent pas les différences comme des obstacles, mais comme des expressions, des manifestations ou des conditions singulières d'une réalité humaine fondamentalement semblable, sauront mieux dialoguer et coopérer pour défınir les bases d'un vivre ensemble harmonieux.

Pour mieux traiter de cette diversité, ce programme réunit dans une même matière l'éthique et la culture religieuse. Là, encore, le programme explique ce choix :

En réunissant dans un même programme l'éthique et la culture religieuse, deux dimensions essentiellement distinctes mais renvoyant l'une et l'autre à des zones d'expression particulièrement sensibles de la diversité, on compte aider les élèves à mener une réflexion critique sur des questions éthiques et à comprendre le fait religieux en pratiquant, dans un esprit d'ouverture, un dialogue orienté vers la recherche du vivre-ensemble ${ }^{13}$.

C'est donc le défi du vivre ensemble posé par le pluralisme qui constitue l'enjeu principal de ce programme. Il en détermine aussi les deux "finalités ": la reconnaissance de l'autre et la poursuite du bien commun, et en définit les trois compétences:

1) réfléchir sur des questions éthiques (C1);

2) manifester une compréhension du phénomène religieux (C2);

3) pratiquer le dialogue (C3).

La première compétence repose sur la prémisse que dans un contexte pluraliste, il n'y a pas de réponse unique à la question de savoir ce qu'il est juste ou ce qu'il est bien de faire; qu'il n'y a pas de solution unique aux problèmes ou aux dilemmes éthiques, que la solution dépend de plusieurs facteurs propres à la situation. Mais aussi qu'entre les diverses solutions, les meilleures sont celles qui s'appuient sur de bonnes raisons. Dans sa réflexion, l'élève est amené

12. Éthique et culture religieuse. Programme du premier cycle et du deuxième cycle du secondaire, Gouvernement du Québec, Ministère de l'Éducation, du Loisir et du Sport, 2008, p. 1. Le document peut être consulté en ligne: [http://www.education.gouv.qc.ca/fileadmin/site_web/documents/ dpse/formation_jeunes/EthiqueCultRel_Secondaire.pdf].

13. Ibid. 
à " examiner la signification des différentes conduites ainsi que les valeurs et les normes que favorisent les membres d'une société en ce qui concerne le vivre-ensemble ${ }^{14}$ ". Il y parvient en analysant les situations d'un point de vue éthique, en examinant une diversité de repères qui orientent la décision et en évaluant les conséquences potentielles des options ou des actions possibles. L'élève apprend donc à réfléchir de manière responsable.

La deuxième compétence, Manifester une compréhension du phénomène religieux, poursuit un double objectif. Un objectif sociohistorique d'abord qui est de permettre à l'élève de se situer dans une tradition, dans une continuité, en développant sa capacité à comprendre son environnement, truffé de symboles et d'expressions du religieux, et à interpréter ces symboles que l'on trouve dans la toponymie, le patrimoine bâti, les arts visuels, le cinéma, les coutumes, etc. Le deuxième objectif, est d'amener l'élève à examiner une diversité de façons de penser, d'être et d'agir et à saisir les raisons qui les sous-tendent.

Enfin, la troisième compétence, Pratiquer le dialogue, se présente comme la compétence charnière ou matricielle qui permet à l'élève de développer les deux autres compétences. Dans un contexte pluraliste où aucune conception du bien ne l'emporte a priori, où aucune croyance ne s'impose, les règles du juste et du vivre ensemble sont produites par le dialogue en vue du consensus. Compétence plus formelle que les deux autres, elle se réalise en amenant l'élève à organiser sa pensée, à interagir avec les autres et à élaborer un point de vue étayé.

\section{Les objections au programme}

Même s'il est le produit d'un consensus social ${ }^{15}$, le programme ÉCR ne fait pas l'unanimité et il a été contesté jusque devant la Cour suprême du Canada. Certains s'y opposent pour des raisons de conviction religieuse, d'autres en vertu du principe de laïcité de l'État; mais dans l'un et l'autre cas, tous craignent que ce nouveau programme n'endoctrine les élèves au multiculturalisme et au relativisme.

Ceux qui s'opposent au programme pour des raisons religieuses dénoncent son caractère obligatoire qui brime selon eux la liberté religieuse reconnue par les chartes canadienne et québécoise, en retirant aux parents le choix des contenus religieux à enseigner aux enfants. Ils rappellent que l'école a l'obligation de respecter ce choix. Ils craignent que " les contenus multi-religieux perturbent les enfants dans leur foi et que l'approche éthique séculière relativise leurs valeurs

14. Ibid., p. 16.

15. Il s'agit d'un programme dont les objectifs et les contenus ont été élaborés par des enseignants du primaire, du secondaire et du collégial, qui a fait l'objet de trois années de travail par des comités d'experts composés d'universitaires des domaines de l'éthique, des sciences des religions et de la didactique de l'enseignement moral, et qui a fait l'objet de consultations auprès de divers groupes de la société civile (Associations de parents et Églises). 
morales ${ }^{16}$ "; ils déplorent la fin de l'enseignement religieux et le vide laissé par ce nouveau programme dans la quête de sens des élèves.

Ceux qui s'opposent au programme en invoquant la laïcité de l'État considèrent qu'il maintient une forme d'enseignement de la religion qui n'a pas sa place à l'école publique. C'est aux arguments de ce deuxième groupe que je m'intéresserai ici. Ces critiques visent principalement la deuxième compétence du programme (Manifester une compréhension du phénomène religieux) et s'en prennent au fait que l'éthique et la culture religieuse soient enseignés conjointement dans un même programme. Le Mouvement laïque québécois s'en inquiète en ces termes :

Les fondements philosophiques universels du droit ne peuvent être présentés comme des équivalents aux dogmes religieux, et c'est malheureusement l'amalgame qui peut facilement se produire lorsque l'éthique et la culture religieuse sont enseignées dans un seul et même programme ${ }^{17}$.

Ainsi, les opposants au programme réclament soit son abolition pure et simple, soit le retrait de la compétence 2. L'ensemble de ces critiques a été rassemblé dans un ouvrage collectif paru récemment intitulé La face cachée $d u$ cours Éthique et culture religieuse ${ }^{18}$. Ce titre exprime littéralement ce que les auteurs pensent du programme ÉCR: l'expression " culture religieuse " ne sert qu'à camoufler l'enseignement religieux qui se poursuit sous une nouvelle appellation. Ils décrivent leur combat comme celui de l'humanisme universel contre une position anti-Lumières défendue par le programme.

Voici les principaux reproches des auteurs de ce livre au programme:

- ce cours résulte d'un compromis avec les autorités religieuses et a été conçu pour préserver des privilèges religieux (Poisson) ;

- aucune place n’y est accordée aux conceptions athées et humanistes (Poisson) ;

- il s'agit d'un endoctrinement au multiculturalisme (Quérin) ;

- les religions sont abordées de manière non critique; il faut les présenter et les dénoncer comme relevant de l'ignorance (Doyon);

- les enseignants sont mal formés et font des choix pédagogiques douteux (Baril) ;

- les manuels véhiculent des stéréotypes sexistes et religieux (El-Mabrouk et Sirois) ;

- le programme entrave l'esprit déductif des élèves (Dulude).

Souvent, ces reproches sont non fondés ou mal informés. Par exemple, Marie-Michelle Poisson affırme que, dans le programme, le mot " éthique "

16. Association des parents catholiques du Québec (APCQC), " La liberté religieuse: Une réponse à Luc Bégin ", 2007. La référence en ligne n'existe plus.

17. Réjean Couture, Henri Laberge, Marie-Michelle Poisson, "Éthique et culture religieuse " dans Cité lä̈que, no 7, automne 2006, [http://www.mlq.qc.ca/7_pub/cl/cl_7/cl_7_ethique_cult_relig. html] (dernière consultation le 2 septembre 2007).

18. Daniel Baril, Normand Baillargeon (dir.), La face cachée du cours Éthique et culture religieuse. Montréal, Boréal, 2016. 
est presque toujours accolé à l'idée de religion - ce qui est faux. Plusieurs de ces reproches ne font pas, non plus, la distinction entre le programme lui-même et la manière dont il est enseigné dans les classes, ou entre le programme et les manuels. D’autres sont fondés sur des prises de positions idéologiques et non sur une analyse et sur une évaluation objective du programme, ou sur une connaissance de la littérature scientifique. Elles confondent fréquemment sentiment antireligieux et esprit critique.

Mais au-delà de l'évidente mauvaise foi de quelques détracteurs du programme, de la nature purement rhétorique de certaines des questions qu'ils soulèvent, de leur refus de lire honnêtement le programme pour y chercher les réponses qui s'y trouvent à leurs questions et de leur persévérance, malgré tout, à le dénigrer, il faut admettre que certains reproches formulés à l'endroit du programme sont des critiques importantes et soulèvent des questions sur lesquelles les défenseurs du programme devront se pencher. C'est le cas de la formation des enseignants et de la qualité des manuels scolaires. Pour d'autres questions, les réponses se trouvent déjà dans le programme, mais demandent à être explicitées et bien expliquées aux enseignants. Ainsi, qu'est-ce que la culture religieuse? Comment enseigner cette culture sans transmettre les croyances dont elle est issue? Comment aborder les éléments plus conflictuels des religions, fortement relayés par l'actualité, tout en respectant la posture d'objectivité imposée aux enseignants? Un enseignement culturel et neutre des religions peut-il contribuer à la formation de l'esprit critique ou au contraire l'empêche-t-il? Comment concilier les croyances qui sont au fondement des religions et l'enseignement de l'éthique critique et humaniste chez de jeunes élèves? Enfin, un cours qui s’intéresse aux différences peut-il mettre en œuvre le vivre ensemble?

L'ensemble de ces questions peut se résumer en une seule: l'école laïque aurait-elle plutôt avantage à laisser de côté l'enseignement des religions, même culturel, pour pouvoir mieux assumer sa mission ${ }^{19}$ ? Étant donné les difficultés que cela pose, ne pourrait-on pas, ne devrait-on pas, simplement s'en abstenir?

\section{Pourquoi un enseignement culturel des religions à l'école laïque?}

Je vois deux raisons importantes à un enseignement culturel des religions à l'école laïque: la première a trait au pluralisme des sociétés contemporaines, l'autre à la radicalisation du laïcisme vers une posture liberticide.

Dans une perspective post-séculière, la laïcité ne s'oppose pas à un enseignement culturel des religions à l'école; et elle ne s'opposerait à un enseignement confessionnel que si toutes les religions présentes dans la société ne recevaient pas le même traitement sous ce rapport. C'est-à-dire s'il n'y avait pas un enseignement confessionnel de toutes les religions présentes dans la

19. Ces questions sont tirées de l'introduction de Baril, Baillargeon (dir.), La face cachée du cours Éthique et culture religieuse. 
société. C'est la première option qui a été choisie par le gouvernement du Québec, la deuxième étant plus exigeante à satisfaire.

Un enseignement culturel des religions présentes dans la société permet aux élèves de prendre acte de la diversité des manières de penser, d'agir et de croire et de mieux comprendre les raisons qui fondent cette diversité. Le pluralisme des sociétés contemporaines est un fait: pluralisme ethnoculturel, moral, religieux. On pourrait vouloir le combattre, le tolérer ou le valoriser. Les deux premières options ne favorisent pas le vivre ensemble et font violence aux droits fondamentaux. Seule la troisième apprend à l'élève le respect d'autrui. En outre, le respect du pluralisme est un des fondements de la démocratie, un régime politique dans lequel est valorisée la possibilité que les individus puissent librement mener leur projet de vie pour autant qu'il ne cause pas de tort à autrui. Ce respect de la liberté d'autrui - impliquant la liberté de conscience et de religion - est facilité lorsque l'on comprend mieux les religions elles-mêmes, leur histoire, le sens des pratiques, des rites, des textes fondateurs, etc. Enfin, la reconnaissance du pluralisme, non seulement comme un fait, mais comme une valeur, me semble un moyen important pour désamorcer l'effet des discours laïcistes et liberticides de plus en plus présents dans certaines sociétés actuelles. Je pense par ailleurs que plusieurs personnes sont d'accord avec ces justifications d'un enseignement culturel ou scientifique des religions. Ce qu'ils craignent davantage, c'est que le programme ÉCR ne soit pas réellement de cette nature. Pourtant, si on lit le programme, on voit que ces craintes ne sont pas fondées.

\section{Qu'est-ce que la « culture religieuse » dans le programme ÉCR?}

Le programme ÉCR prend soin de bien définir ce qu'il entend par " culture religieuse " :

[C]ompréhension éclairée des multiples expressions du religieux présentes dans la culture québécoise et dans le monde. Elle est dite " culturelle " parce qu'elle est axée sur la capacité de saisir le champ religieux dans ses diverses expressions dans le temps et l'espace. Elle permet la compréhension des signes dans lesquels s'exprime l'expérience religieuse des individus et des groupes qui contribuent à façonner la société. De plus, elle ne propose pas aux élèves un univers particulier de croyances et de repères moraux ${ }^{20}$.

Il n'est donc pas question d'un enseignement confessionnel ; il n'est pas question non plus de quête de sens, ni même de spiritualité. La religion est abordée comme un phénomène des sociétés humaines, sans l'angle des mythes, des rites, des pratiques, etc. ; et c'est sous cet angle phénoménologique que sont traitées les croyances propres à chaque tradition religieuse. Il est clair en tout cas que celles-ci ne sont pas " transmises ${ }^{21}$ ".

20. Éthique et culture religieuse, préambule non paginé, $2^{\mathrm{e}}$ feuille.

21. Dans un autre texte, je précisais ce qui suit: "Il importe de préciser que le programme québécois veut développer chez les élèves une culture religieuse, au singulier. Il ne vise pas l'acquisition 
Cette distance épistémologique qu'impose une approche phénoménologique ne suffit pas à satisfaire certains des opposants au programme qui souhaitent que l'enseignant aille jusqu'à prendre parti, scientifiquement, en dénonçant certaines croyances religieuses comme fausses, ou qu'il se prononce sur des éléments plus conflictuels des religions, comme les inégalités entre les hommes et les femmes. Deux raisons justifient à mon sens qu'il ne le fasse pas: la posture de réserve et d'objectivité qui lui est imposée par le programme et l'importance d'amener l'élève à faire la distinction entre ce qui relève du discours scientifique et ce qui relève du discours religieux.

La posture de l'enseignant, considérant l'influence qu'il exerce sur les élèves, est décrite et justifiée en deux endroits du programme. D’abord dans le préambule où l'accent est mis sur le respect des croyances transmises par la famille, dans des limites néanmoins précisées: la dignité des personnes et le bien commun.

Puisque ces disciplines [l'éthique et la culture religieuse] renvoient à des dynamiques personnelles et familiales complexes et parfois délicates, un devoir supplémentaire de réserve et de respect s'impose au personnel enseignant, qui ne doit pas faire valoir ses croyances ni ses points de vue. Cependant, lorsqu'une opinion émise [par des élèves] porte atteinte à la dignité de la personne ou que des actions proposées compromettent le bien commun, l'enseignant intervient en se référant aux deux finalités du programme [la reconnaissance de l'autre et la poursuite du bien commun]. Il lui faut aussi cultiver l'art du questionnement en faisant la promotion de valeurs telles que l'ouverture à la diversité, le respect des convictions, la reconnaissance de soi et des autres, et la recherche du bien commun ${ }^{22}$.

Puis, dans une section intitulée "Contexte pédagogique ", qui présente le rôle de l'enseignant et sa posture professionnelle:

Comme les questions éthiques qui se posent dans le monde contemporain sont complexes, il doit savoir repérer des tensions, des valeurs et des normes qui s'y rattachent et faire preuve de rigueur lorsqu'il les traite en classe. Il doit également aborder les expressions du religieux avec tact afin d'assurer le respect de la liberté de conscience et de religion de chacun. Dans ce contexte, il lui faut comprendre l'importance de conserver une distance critique à l'égard de sa propre vision du monde, notamment de ses convictions, de ses valeurs et de ses croyances.

Pour favoriser chez les élèves une réflexion sur des questions éthiques ou une compréhension du phénomène religieux, l'enseignant fait preuve d'un jugement professionnel empreint

par les élèves d'une connaissance des cultures religieuses. L'élève doit devenir capable de reconnaître des manifestations du religieux, de les relier à une tradition religieuse particulière et d'en saisir la signification. Pour cela, il faut certes posséder des connaissances sur les traditions religieuses, mais cela n'est pas l'objectif premier. Ce qui est mis de l'avant, c'est une approche phénoménologique du religieux. " (p. 132) ; "Cette approche phénoménologique est controversée, d'une part parce qu'elle ne permet pas d'accéder à la signification profonde de l'expérience religieuse; d'autre part parce qu'elle n'enseigne pas les démarches ou les savoirs issus des sciences humaines sur les religions. Mais dans la perspective du vivre ensemble, cette approche est plus profitable parce que comprendre le phénomène religieux devient comprendre le sens que l'autre qui appartient à une tradition religieuse particulière attribue à des expressions du religieux. Elle met en œuvre une herméneutique de l'autre. " (p. 137); Dany Rondeau, "Éthique et culture religieuse en dialogue. Regard sur le programme québécois ", Zeitschrift für Religionskunde - Revue de didactique des sciences des religions 2, 2016, p. 129-140. En ligne: [http://zfrk-rdsr.ch/images/Ausgaben_ZFRK/Rubriken/2016_02_Rondeau-ZFRK_2-2016.pdf].

22. Éthique et culture religieuse, préambule non paginé, $2^{\mathrm{e}}$ feuille. 
d'objectivité et d'impartialité. Ainsi, pour ne pas influencer les élèves dans l'élaboration de leur point de vue, il s'abstient de donner le sien. Lorsqu'une opinion émise porte atteinte à la dignité de la personne ou que des actions proposées compromettent le bien commun, l'enseignant intervient en se référant aux finalités du programme ${ }^{23}$.

En outre, en ne dénonçant pas les " faussetés ", les " mensonges », les « impostures " proférés par les religions - qu'il n'aborde pas pour autant comme des vérités, mais dans toute leur relativité (ce qui vaut d'ailleurs au programme les reproches de ceux qui s'y opposent pour des raisons religieuses), l'enseignant permet peu à peu à l'élève de comprendre la différence et la distance entre science et religion, entre le domaine de la connaissance et le domaine du croire. L'enseignant n'a pas à dire que telle ou telle croyance est fausse, mais à faire comprendre à l'élève de quel lieu de l'expérience humaine relève le phénomène religieux ${ }^{24}$. On peut penser qu'à la lumière de cet enseignement, l'élève sera capable, à la longue, de mieux comprendre les événements de l'actualité, dont ceux qui sont liés aux religions, et de comprendre aussi comment des religions sont instrumentalisées à des fins politiques ou idéologiques. L'enseignement de la culture religieuse contribue donc elle aussi de manière importante au développement et à l'exercice de l'esprit critique.

\section{Comment concilier les croyances qui sont au fondement des religions et l'enseignement de l'éthique critique et humaniste chez de jeunes élèves?}

Cette question est importante et ce qui précède y répond en partie. Il faut y ajouter que c'est principalement la compétence 1, Réfléchir sur des questions éthiques, et la compétence 3, Pratiquer le dialogue, qui introduisent l'élève à l'éthique critique et humaniste. Mais lorsqu'il travaille ces deux compétences, l'élève doit se référer à des repères: culturels, scientifiques, juridiques et, s'il y a lieu, religieux, parce qu'ils font aussi partie des repères culturels. En effet, les moyens déployés par les compétences 1 et 3 contribuent à aborder les croyances comme un type de repères parmi d'autres, mais un type de repères avec ses caractéristiques propres, distinctes des repères juridiques ou scientifiques, par exemple. C'est le rôle de l'enseignant d'introduire ces distinctions. La prise en compte de manière critique de différents repères amène l'élève à tenir compte des différences dans la recherche des options les plus justes et responsables.

23. Ibid., p. 12.

24. Une des premières situations d'apprentissage fournies aux enseignants par le ministère de l'Éducation dans le cadre de la formation continue des enseignants consistait à aborder les récits religieux de la création en demandant aux élèves de les comparer avec la théorie de l'évolution. Cette situation d'apprentissage s'adressait aux élèves de $4^{\mathrm{e}}$ année du primaire (9-10 ans). La vidéo produite montrait que les élèves ne confondaient pas les registres de discours. 


\section{Conclusion}

Le cheval de bataille des opposants au programme ÉCR est celui de la laïcité et de la sécularisation. L'école publique est une institution de l'État et la neutralité de l'État, principe phare de la laïcité, commande que l'État ne se mêle pas de religion. $\mathrm{Au}$-delà de l'hostilité manifeste de certains à l'égard de la religion, au prix même de la connaissance et de la culture, les tenants de cette position considèrent que la société québécoise n'est pas totalement sécularisée et qu'il faut être vigilant à l'égard des initiatives qui auraient pour effet de réintroduire le religieux au sein du politique. C'est dans cette perspective qu'il faut comprendre leurs réticences à l'égard du programme ÉCR, et celle-ci est certainement à prendre au sérieux puisque des groupes religieux ont vu dans ce programme une occasion à saisir pour " retourner " dans l'école ${ }^{25}$.

Parmi les défenseurs du programme, il s'en trouve certainement quelques-uns pour plaider que l'heure est venue de réconcilier la foi et la raison en permettant à la première un accès au sens par rapport auquel la seconde serait devenue impuissante. Mais à mon avis, la majorité des défenseurs du programme sont plus pragmatiques: ils accordent une importance à l'éducation au pluralisme en raison de son potentiel pour mieux vivre ensemble. Il ne s'agit pas que l'État faillisse au principe de laïcité en ajustant le politique aux différences; il faut plutôt que les personnes qui composent la société, elles, puissent apprendre à les reconnaître, à les respecter et à en voir la richesse. C'est ainsi qu'un cours qui s'intéresse aux différences peut mettre en œuvre le vivre ensemble. Une telle position relève aussi d'une posture post-séculière.

25. Il importe toutefois de préciser que les écoles n’ont pas, de leur côté, ouvert leurs portes à ces groupes religieux. 
